\title{
Teaching Experience and Views of Pronunciation Formative Assessment
}

\author{
Hassan Qutub \\ English Language Institute, King Abdulaziz University \\ Jeddah, Saudi Arabia \\ E-mail: hqutub@kau.edu.sa
}

Received: October 10, 2021 Accepted: October 28, $2021 \quad$ Published: November 4, 2021

doi:10.5296/ijl.v13i5.19144

URL: https://doi.org/10.5296/ijl.v13i5.19144

\begin{abstract}
The current study aimed at investigating the differences between novice and expert Arab EFL teachers in their views of providing pronunciation corrective feedback to their students. Four teachers were recruited for the study. Two novice teachers and two experienced teachers. Both groups of teachers were interviewed about their views of providing pronunciation corrective feedback. Interview data analysis revealed the existence of six major differences between novice and experienced teachers in their views of pronunciation corrective feedback. These differences included timing, frequency, considering students' proficiency level, considering the skill being taught, focus on form and/or meaning, and the range of pronunciation corrective feedback techniques used. Further suggestions included incorporating a pronunciation corrective feedback component in teacher development as well as professional training programs.
\end{abstract}

Keywords: Formative assessment, Corrective feedback, Second language pronunciation, Novice teachers, Teaching experience

\section{Introduction}

Language learning is viewed as an interactive process in which teachers assist learners to maximize learning outcomes (Gass \& Mackey, 2007). One way to maximize learning outcomes, is through what is known as "assessment for learning" (Black, 1986), which is also referred to as formative assessment. Formative assessment is defined by Black and Wiliam (1998) "as encompassing all those activities undertaken by teachers, and/or by their students, which provide information to be used as feedback to modify the teaching and learning 
activities in which they are engaged" (p.7). From the definition above, it is evident that corrective feedback represents a useful tool that is used to modify both teaching and learning; hence, corrective feedback has attracted the focus of many methodologists as well as second language acquisition (SLA) researchers (e.g., Ellis, 2009; Li, 2010; Lightbown \& Spada, 1990; Lyster, 1998; Sheen, 2004).

In SLA research, corrective feedback is viewed as one type of negative feedback, which is usually a response to a linguistic error produced by the learner (Ellis, 2009). Researchers working within the interactionist SLA framework claim that negative feedback plays a salient role in second language learning through providing learners with opportunities to notice their errors, which if happened repeatedly, can facilitate turning linguistic input into intake (Ellis, 2007; Gass \& Mackey, 2007). Corrective feedback can take several forms, including explicit correction, recasts, elicitation, metalinguistic clues, clarification requests, and repetition (Lyster \& Ranta, 1997). Classroom oriented SLA research shows that different forms of corrective feedback exhibit varying degrees of effectiveness in different language classroom settings (Bitchener, Young, \& Cameron, 2005; Lyster, 1998; Lyster \& Ranta, 1997; Nicholas, Lightbown, \& Spada, 2001; Sheen, 2006). The effectiveness of corrective feedback is affected by different variables including the language skills involved (Bitchener, Young \& Cameron, 2005; Dlask \& Krekeler, 2013), teachers' non-verbal behavior (Guvendir, 2011), learners' perceptions of corrective feedback (Hedgcock \& Lefkowitz, 1994), teachers' knowledge of corrective feedback (Mori, 2011), learners' motivation (Uzum, 2010), and teaching experience (Maclellan, 2004). To summarize, the variables that can influence the effectiveness of corrective feedback can be teacher related, learner related, and/or skill related.

Teachers' knowledge of corrective feedback has proven to have a powerful impact on the effectiveness of the corrective feedback they provide to their learners (Mori, 2011). This view has been supported by many researchers who stressed the importance of providing teachers with the necessary knowledge of corrective feedback in teacher education and professional development programs (e.g., Ellis, 2009; Van Ha \& Murray 2021). However, teachers' knowledge of corrective feedback and their beliefs of its importance will not necessarily be translated in their classroom practices (Hernández Méndez \& Cruz, 2012; Kartchava, 2006), which makes this issue a fertile ground for further investigation. Therefore, teaching experience is an important variable that can affect the effectiveness of formative assessment in general and corrective feedback in particular (Maclellan, 2004; Huang, 2013; Saito, 2014).

Although corrective feedback has been investigated repeatedly in the literature, only a few studies have focused on pronunciation corrective feedback. Moreover, only a very limited number of studies have investigated pronunciation corrective feedback in an Arabic EFL context. Furthermore, providing pronunciation corrective feedback has rarely been investigated in relation to teaching experience. Therefore, given that teacher characteristics play an integral role in the effectiveness of corrective feedback, the current study aims at investigating the possible connection between teachers' years of teaching experience and their views of providing students with pronunciation corrective feedback.

In order to achieve the above aim, the following research question was addressed: 
What are Arab experienced teachers' views of pronunciation corrective feedback in an EFL classroom, as compared to novice teachers?

\section{Background}

The term "formative evaluation" was first used by Scriven (1967) to account for the continuous development of the curriculum. Over the next two decades the term "formative" was not frequently used in the literature; however, some studies examined the integration of assessment within classroom instruction, which resulted in the emergence of what is knows as Cognitively Guided Instruction (CGI) (Wiliam, 2011). CGI was examined in a research project by Carpenter, Fennema, Peterson, Chiang, and Loef (1989) in which they concluded that students who were taught by CGI teachers, achieved remarkably better results compared to other students. This was followed by a growing interest in the literature to investigate the effectiveness of formative assessment on students' achievement. In a review of about 600 studies that are potentially relevant to classroom formative assessment, Black and Wiliam (1998) concluded that the use of assessment to inform classroom instruction could dramatically increase the speed of students' learning.

Despite the agreement in the literature about its effectiveness, formative assessment's definition remains controversial. In the literature, formative assessment is usually compared with summative assessment, which refers to the evaluation of learners' achievement out of a given course or program (Harlen \& James, 1997). However, the distinction between the formative and summative evaluation is not that simple. Wiliam (2011) notes that even summative evaluation procedures can be used formatively, and he provides an example of a teacher who did not score one of the tests that she gave to her students. Instead, she divided them into groups and asked them to work together in order to arrive at the best possible answers. In trying to clear the ambiguity of the distinction between formative and summative evaluation, Wiliam and Black (1996) claim that it is meaningful to view the distinction in terms of the way that assessment data is used, and not the way in which the assessment is conducted.

The majority of attempts to generate a holistic definition for formative assessment assign a central role for feedback. Feedback can either be positive or negative. Positive feedback confirms a learner's response and provides motivational support for the learner that can aid further learning (Ellis, 2009). In contrast, negative feedback is used to indicate that the learner has used an incorrect linguistic form (Ellis, 2009). Corrective feedback is one form of negative feedback that aims at providing the learner who has committed a linguistic error with a corrective response (Ellis, Loewen, \& Erlam, 2006). The role of corrective feedback in facilitating second language acquisition (SLA) has been debatable. Behaviorist views of SLA did not envision corrective feedback as a facilitator of second language learning. According the behaviorist account, corrective feedback was seen as a "punishment" which can discourage further learning (VanPatten \& Williams, 2007). In his monitor theory, Krashen (1982) argued that using corrective feedback could negatively affect second language learning. He claimed that corrective feedback can make learners self-conscious about their language production; as a result, they will avoid producing more complex linguistic forms. He also claimed that the use of corrective feedback can only promote the development of learners" "learned knowledge" 
and does not contribute to the development of their "acquired knowledge". However, although Krashen did not recommend the use of corrective feedback for language learners, he claimed that using corrective feedback with simple rules (e.g., third person -s) only when learners have the time to access their "learned knowledge" can help learners in monitoring their linguistic production.

However, interactionist SLA researchers view corrective feedback as a facilitator for second language learning (Gass \& Mackey, 2007). In his noticing hypothesis, Schmidt (1990) argued that corrective feedback could help learners to raise their awareness (i.e., through noticing) of correct linguistic forms that can help them in monitoring the accuracy of their language production. Noticing, which can result from corrective feedback, has been viewed as a central component of the Associative-Cognitive CREED (i.e., Construction-based, Rational, Exemplar-driven, Emergent, and Dialectic) approach to SLA. According to the Associative-Cognitive CREED, second language learning is affected by the frequency and salience of the input. Ellis (2007) uses the metaphor of a detector in the learners' cognitive system. Every detector has a threshold level that, when exceeded as a result of noticing, becomes active and fires. After multiple firing, the threshold level of that detector decreases; as a result, with repeated noticing, the learner will likely acquire the target language form. This shows that corrective feedback can facilitate second language learning through increasing the saliency of the linguistic forms so that they are noticed more rapidly, and then acquired as a result of repeated exposure.

From a pedagogical perspective, the use of corrective feedback has not been recommended by communicative language teaching (CLT), which focused mainly on promoting students' fluency, as opposed to accuracy, in their production of the target language (Schmidt, 1983). In order to reach a balance between fluency and accuracy in students' production, Lightbown and Spada (1990) have suggested that "accuracy, fluency, and overall communicative skills are probably best developed through instruction that is primarily meaning-based but in which guidance is provided through timely form-focused activities and correction in context" (p.443). This shows that using form-focused instruction along with meaning-based CLT can help in reaching a balance between fluency and accuracy in students' target language production, and according to Lyster and Ranta (1997), form-focused instruction can be performed through providing corrective feedback.

Recent research has moved from examining the theoretical and pedagogical perspectives on the effectiveness of corrective feedback towards investigating the techniques of corrective feedback that can foster the process of second language learning (Ellis, 2009). Corrective feedback can be delivered through several techniques. Ellis, Loewen, and Erlam (2006) have identified three major components that corrective feedback can include. These include; an indicator showing that the leaner has committed an error, correct linguistic form supplied by another interlocutor, and/ or metalinguistic information describing the nature of he error committed by the learner. In a more detailed description, Lyster and Ranta (1997) have identified six techniques of corrective feedback. These include;

1- explicit correction: in which the learner's error is explicitly corrected, 
2- recasts: reformulating all of or part of the learner's response,

3- elicitation: using prompts to trigger the learner to reformulate his/her own response,

4- metalinguistic clues: providing comments, questions, and/or information related the learner's response,

5- clarification requests: asking the learner to clarify his/her response, and

6- repetition: repeating the learner's response to highlight the linguistic error.

The effectiveness of corrective feedback techniques has been examined in relation to different language skills; however, their effectiveness with respect to pronunciation instruction has not received much attention (Foote, Trofimovich, Collins, \& Urzúa, 2013). Several studies have examined the effectiveness of different corrective feedback techniques in improving students' pronunciation (Dlaska \& Krekeler, 2013; Ellis, Basturkmen, \& Loewen, 2001; Lyster, 1998; Lyster \& Saito, 2010; Saito; 2011; Saito \& Lyster, 2012a; 2012b). Although the majority of the studies listed above concluded that recasts are the most effective corrective feedback technique when addressing pronunciation errors, it is still hard to make such a generalization. The context in which the study was conducted (Razfar, 2010), students' perceptions (Carpenter, Jeon, MacGregor, \& Mackey, 2006; Mackey, Gass, \& McDonough, 2000) as well as teachers' beliefs and practices with respect to pronunciation corrective feedback (Hernández Méndez \& Cruz, 2012; Murphy, 2011) are all major factors that influence the effectiveness of corrective feedback.

Teachers' views and practices play an integral role in the effectiveness of pronunciation corrective feedback. In a study that examined teachers' practices in providing students with pronunciation corrective feedback, Murphy (2011) conducted a survey for 36 English as a second language (ESL) teachers about their pronunciation teaching practices. She concluded that $97 \%$ of the teachers taught pronunciation at least once per-month, and $75 \%$ reported that they have taught pronunciation more than once a week. Finally, around $90 \%$ of the teachers reported that they used listen-and-repeat activities or provided pronunciation corrective feedback during read-aloud activities.

In a more recent effort, Foote et al. (2013) conducted a longitudinal, corpus-based study to explore teachers' behaviors in teaching second language pronunciation. The researchers transcribed 40 hours of videotaped lessons taught by three English language teachers. The transcribed videos were then coded for pronunciation teaching episodes, which were then analyzed for the type, and impact on second language learning. The results reveled the infrequency of pronunciation teaching episodes, which accounted only for $10 \%$ of the language episodes. Results also showed that pronunciation teaching only targeted individual sounds and neglected prosodic features.

In their descriptive study, Hernández Méndez and Cruz (2012) examined EFL teachers' perceptions and practices with respect to oral corrective feedback in a major Mexican university. They interviewed five EFL teachers to explore their perceptions of oral corrective feedback. To explore teachers' practices with respect to oral corrective feedback, they used a 
questionnaire that they distributed to 40 participants; however, only 15 returned it back to the researchers. The study took different error types into account including pronunciation errors. Results indicated that teachers exhibited positive perceptions towards oral corrective feedback. However, some teachers viewed oral corrective feedback as an optional teaching practice, bearing in mind the emotions of the students. Implicit and unfocused oral corrective feedback were the most common in teachers' practices.

In another effort exploring teacher characteristics in relation corrective feedback, Rahimi and Zhang (2015) conducted a study investigating the differences between novice and experienced teachers' cognitions about the effectiveness of corrective feedback in an EFL context. Forty nonnative English teachers 20 of which were experienced (i.e., with 4 or more yeas of teaching experience) and 20 were novice (i.e., with two or less years of teaching experience) participated in the study. The researchers used a questionnaire and follow-up interviews to collect data for their study. Results indicated that EFL teachers' experience could significantly influence their cognitions about the effectiveness of corrective feedback. Experienced teachers took into consideration learners' factors including proficiency level and anxiety when providing corrective feedback. They also considered factors like error type and frequency as well as the skill being taught in providing corrective feedback. Regarding the timing of corrective feedback, most of the experienced teachers preferred providing corrective feedback as soon as the error occurs. In contrast, novice teachers resorted to their own language learning experience when providing corrective feedback, which reflected inflexibility and exclusion of many learner-dependent factors. In terms of the timing of providing corrective feedback, most of the novice teachers chose to delay providing corrective feedback.

In a more recent study, Moradkhani \& Goodarzi (2020) attempted to compare teachers' beliefs about oral corrective feedback and their classroom practices. Data was collected from three female EFL teachers through videorecording three sessions of their class time followed by stimulated recall interviews. Results showed that experienced teachers showed more variety in the corrective feedback types used in actual teaching as compared to novice teachers, who used a limited range of corrective feedback types. Moreover, novice teachers continuously resorted to their language learning experience in justifying their oral corrective feedback practices.

In general, the above studies show variability in teachers' practices with respect to oral corrective feedback. For example, Murphy (2011) showed high percentages of teacher corrective feedback use, whereas Foote et al. (2013) showed that corrective feedback did not receive much attention. Even though both studies were in an ESL context, there was a big variation in their findings. This variation might go back the methods used in data collection. Murphy (2011) used surveys to capture teachers' practices with respect to pronunciation corrective feedback. In contrast, Foote et al. (2013) as well as Moradkhani \& Goodarzi (2020) used a corpus of actual videotaped classroom interactions that were transcribed and coded for pronunciation corrective feedback episodes, which is considered more accurate compared to surveys alone. Rahimi and Zhang (2015) al well as Moradkhani \& Goodarzi (2020) both agreed that novice teachers resorted to their own language learning experience when justifying the use of oral corrective feedback in their actual teaching. 


\section{MlMacrothink}

International Journal of Linguistics

ISSN 1948-5425

2021, Vol. 13, No. 5

The studies that compared teachers views and practices in terms or oral corrective feedback (i.e., Basturkmen, Loewen, \& Ellis, 2004; Hernández Méndez \& Cruz, 2012; Kartchava, 2006; Yoshida, 2010) did not focus on pronunciation corrective feedback per se; however, they investigated a number of linguistic errors including phonological errors. Moreover, none of the five studies discussed above was conducted in an Arabic EFL context. Therefore, the current study investigated teachers' years of teaching experience in relation to their views of providing students with pronunciation corrective feedback in a Saudi Arabian EFL context.

\section{Methods}

\subsection{Participants}

The current study was conducted in an English language institute that teaches English as a part of a foundation year program for first year university students. The institute is housed in a Saudi Arabian university located in an urban setting. The study recruited four Arab EFL teachers $(\mathrm{N}=4)$. Two teachers were novice teachers with less than five years of EFL teaching experience. The other two teachers were more experiences with more than 15 years of EFL teaching experience.

The researcher explored these teachers' views of towards pronunciation corrective feedback through semi-structured interviews. It should be noted that the researcher went through all the ethical requirements of the host institution and obtained a signed informed consent form from each participant.

\subsection{Data Collection}

Interviews were used to compare between novice and experienced Arab EFL teachers' views about pronunciation corrective feedback. Interviews have been repeatedly used by researchers to capture teachers' views towards corrective feedback (e.g., Basturkmen, Loewen, \& Ellis, 2004; Hernández Méndez \& Cruz, 2012; Moradkhani \& Goodarzi, 2020). The researcher used simi-structured interviews. Semi-structured interviews allow researchers to obtain comparable data related to participants' perceptions of a specific theme or topic within its relevant context (Edwards \& Holland, 2013). The questions used to guide the interviews were revised by two established researchers in the field to ensure their validity. Interviews were recorded through Audacity computer software at (16 kHz, 32 bits) using an external microphone. The interviews' duration ranged from 29 to 37 minutes. Each participant was interviewed individually in a quiet room. Interviews were then transcribed in preparation for them to be analyzed for reoccurring themes.

\subsection{Research Design}

The current study followed the qualitative approach utilizing a research design based on thematic analysis, which is defined as "a method for identifying, analyzing, and reporting patterns (themes) within data" (Braun \& Clarke, 2006: 79). Thematic analysis helps researchers to develop themes within raw data, and to interpret them in more depth through identifying explicit as well as implicit ideas. Moreover, thematic analysis is a flexible method in which researches can provide a detailed interpretation of qualitative data. It also can help 
researchers highlight similarities and differences between the participants in a given dataset (Braun \& Clarke, 2006). Given that the current study aimed at exploring the differences between the views of novice and experienced Arab EFL teachers in their views of providing oral corrective feedback, thematic analysis is a suitable research design for the purpose of the study.

\section{Data Analysis}

This section demonstrates the thematic analysis emerging from the transcribed interviews. This demonstration is guided by the question that the current study investigated.

\subsection{Novice Teachers' Views of Pronunciation Corrective Feedback}

The analysis of the four transcribed interviews showed that novice teachers prefer to provide students with corrective feedback immediately as soon as the error occurs. However, novice teachers reported correcting students only 50 to 60 percent of the time. Providing immediate corrective feedback was justified by the possibility of students learning the "incorrect" pronunciation and it will be "internalized in their language system", which will make it difficult for them to learn the "correct" pronunciation later. Furthermore, novice teachers agreed that pronunciation corrective feedback should be avoided whenever possible with beginner students in order not to demotivate them or to discourage them from oral production. Both novice teachers reported focusing on the most two common standardized accents when it comes to judging the correctness of students' pronunciation (i.e., Received Pronunciation and American English) regardless of intelligibility. This was justified by the fact that a foreign accent can affect listeners' judgments especially in situations like job interviews which students are likely to face in the future. Finally, novice teachers reported only implementing limited techniques of pronunciation corrective feedback in their classrooms. This included recasts and explicit correction only.

\subsection{Experienced Teachers' Views of Pronunciation Corrective Feedback}

Experienced teachers were more patient when providing students with pronunciation corrective feedback as compared to the novice teachers. Both experienced teachers agreed on the importance of providing pronunciation corrective feedback to their students; however, they reported that it should be done with caution taking individual student personality into account. The experienced teachers reported that providing pronunciation corrective feedback in their classes is dependent on the language components being taught. For example, they provided more pronunciation corrective feedback when teaching vocabulary and reading than when they are teaching grammar. Moreover, experienced teachers reported giving more prominence to ineligibility than to correctness when it comes to correcting students' pronunciation. That is, as long as students were understood and the meaning is conveyed, they did not interrupt them with corrective feedback. Experienced teachers agreed on providing more pronunciation corrective feedback to beginner students as compared to more advanced students. Finally, experienced teachers reported providing a wide range of pronunciation corrective feedback including explicit correction, recasts, metalinguistic clues, clarification requests, and repetition. 


\section{Discussion}

The interview data presented above show that great differences exist between novice and experienced teachers in their views of pronunciation corrective feedback. The first difference was the timing in which the pronunciation corrective feedback is provided. Novice teachers agreed that corrective feedback should be provided immediately after a mispronunciation. Experienced teachers, on the other hand, were more patient when providing pronunciation corrective feedback.

The second difference was the frequency of the pronunciation corrective feedback. Novice teachers provided more frequent pronunciation corrective feedback as compared to experienced teachers, who took several factors into consideration including students' personality when providing pronunciation corrective feedback. Novice teachers in contrast did not report taking student personality into consideration when providing pronunciation corrective feedback. Differences in the timing and frequency between novice and experienced teachers may be explained by the novice teachers' lack of experience and resorting to their own language learning experience when providing pronunciation corrective feedback and not to the characteristics of the cohort of students they are teaching. This view was shared by Rahimi and Zang (2015) as well as Moradkhani and Goodarzi (2020) who reported that novice teachers resorted to their own language learning experience when providing pronunciation corrective feedback.

The third difference between novice and experienced teachers in their views of providing pronunciation corrective feedback was related to the proficiency level of the students. Novice teachers avoided providing pronunciation corrective feedback for beginning levels, whereas experienced teachers provided more corrective feedback for the beginning levels. The novice teachers were more impulsive in providing pronunciation corrective feedback. They justified providing less corrective feedback for beginning students by their concern to affect student motivation. However, the impulsive nature of their pronunciation corrective feedback might have more negative effect on the beginning students. A more balanced approach to providing pronunciation corrective feedback was exhibited by the experiences teachers who were more patient and provided corrective feedback to all levels but with caution taking students personality into account.

The fourth difference was that novice teachers did not take the language skill and component being taught into consideration when providing pronunciation corrective feedback. Experienced teachers, on the other hand, reported providing more pronunciation corrective feedback when teaching vocabulary and reading. Differences between novice and experienced teachers in taking the students' level and the language component being taught might also be explained by novice teachers' dependence on their own learning experiences instead of understanding the characteristics of the cohort of students they are teaching. This was echoed by Rahimi and Zang (2015) who claimed that novice teachers' dependence on their language learning experiences can lead to inflexibility and exclusion of many learner-dependent factors. This also comes in line with the findings of Moradkhani and Goodarzi (2020). 


\section{Mll Macrothink}

International Journal of Linguistics

ISSN 1948-5425

2021, Vol. 13, No. 5

The fifth difference between novice and experienced teachers in their views of providing pronunciation corrective feedback was that novice teachers focused more on form (i.e., correct pronunciation) whereas experienced teachers focused more on meaning (i.e., intelligibility). Novice teachers have justified their focus on "correct" pronunciation by that a foreign accent might have a negative impact on the students if they were in a gatekeeping encounter (e.g., job interview) where the listeners might judge the speaker based on his/her accent. This can be explained by claim stating that non-native speakers can be sensitive to their accent in gatekeeping encounters (Qutub, 2014). However, correctness in pronunciation is very relevant as it is very difficult to define a reference-point for correctness or find a unified accent for native speakers of English (see Munro \& Derwing, 2015). The experienced teachers showed a more mature and inclusive approach in providing pronunciation corrective feedback based on the meaning conveyed.

The sixth and last difference found in this study between novice and experienced teachers in their views of providing pronunciation corrective feedback was related to the range of pronunciation corrective feedback techniques used. Novice teachers used a limited range of pronunciation corrective feedback techniques, whereas experienced teachers used a variety of techniques. This might be explained by novice teachers lack of experience and probably limited training. This finding comes in line with Moradkhani \& Goodarzi (2020) who reported that novice teachers used a limited range of pronunciation corrective feedback techniques.

\section{Conclusion}

The current study attempted to explore the possible impact of Arab EFL teachers' teaching experience on their views of pronunciation formative assessment, and specifically pronunciation corrective feedback. Previous research on the linking EFL teachers' teaching experience to formative assessment is limited; therefore, the current study provides an additional effort towards a better understanding of the nature o that relationship. Interview data analysis revealed the existence of six major differences between novice and experienced teachers in their views of pronunciation corrective feedback. These differences included timing, frequency, considering students' proficiency level, considering the skill being taught, focus on form and/or meaning, and the range of pronunciation corrective feedback techniques used.

Based on the above results, the researcher suggests including practical application drills in teacher preparation programs that focus on providing pronunciation corrective feedback. Moreover, the researcher suggests providing novice teachers with professional training on utilizing the different techniques of pronunciation corrective feedback taking into account student characteristics and the language skills and components being taught.

Limitations of the current study include the limited number of participants recruited including only 4 teachers. Future research may explore the possible impact of Arab EFL teachers' teaching experience on their views of pronunciation formative assessment by recruiting a wider range of participants. Another suggestion to avoid this limitation in future research is through conducting a longitudinal study that explores the change that is likely to occur in novice teachers' views of providing pronunciation corrective feedback over a prolonged period of time. 


\section{NI Macrothink}

International Journal of Linguistics

ISSN 1948-5425

2021, Vol. 13, No. 5

Future research may explore the relationship between teaching experience and views of pronunciation corrective feedback in more depth by collecting data from a wider range of sources. This can include videotaping and analyzing classroom interaction for pronunciation corrective feedback episodes and stimulated recall interviews which can possibly provide a better understanding of the nature of the relationship between teaching experience and pronunciation corrective feedback.

\section{References}

Basturkmen, H., Loewen, S., \& Ellis, R. (2004). Teachers' stated beliefs about incidental focus on form and their classroom practices. Applied Linguistics, 25(2), 243-272.

Bitchener, J., Young, S., \& Cameron, D. (2005). The effect of different types of corrective feedback on ESL student writing. Journal of Second Language Writing, 14(3), 191-205.

Black, H. (1986). Assessment for learning. In D. L. Nuttall (Ed.), Assessing educational achievement (pp. 7-18). London: Falmer Press.

Black, P., \& Wiliam, D. (1998). Assessment and classroom learning. Assessment in Education, 5(1), 7-74.

Braun, V., \& Clarke, V. (2006). Using thematic analysis in psychology. Qualitative Research in Psychology, 3(2), 77-101.

Carpenter, H., Jeon, K. S., MacGregor, D., \& Mackey, A. (2006). Learner's Interpretations of Recasts. Studies in Second Language Acquisition, 28(2), 209-236.

Carpenter, T. P., Fennema, E., Peterson, P. L., Chiang, C. P., \& Loef, M. (1989). Using knowledge of children's mathematics thinking in classroom teaching: An experimental study. American Educational Research Journal, 26(4), 499-531.

Dlaska, A., \& Krekeler, C. (2013). The short-term effects of individual corrective feedback on L2 pronunciation. System, 41(1), 25-37.

Edwards, R., \& Holland, J. (2013). What is qualitative interviewing?. UK: Bloomsbury.

Ellis, N. (2007). The associative-cognitive CREED. In B. VanPatten, \& J. Williams, J. (Eds.), Theories in second language acquisition: An introduction (pp. 77-95). Mahwah, NJ: Erlbaum.

Ellis, R. (2009). Corrective feedback and teacher development. L2 Journal, 1(1), 3-18.

Ellis, R., Basturkmen, H., \& Loewen, S. (2001). Learner uptake in communicative ESL lessons. Language Learning, 51(2), 281-318.

Ellis, R., Loewen, S., \& Erlam, R. (2006). Implicit and explicit corrective feedback and the acquisition of L2 grammar. Studies in Second Language Acquisition, 28(2), 339.

Foote, J. A., Trofimovich, P., Collins, L., \& Urzúa, F. S. (2013). Pronunciation teaching practices in communicative second language classes. The Language Learning Journal, (ahead-of-print), 1-16. 


\section{Macrothink}

International Journal of Linguistics

ISSN 1948-5425

2021, Vol. 13, No. 5

Gass, S., \& Mackey, A. (2007). Input, interaction, and output in second language acquisition. In B. VanPatten, \& J. Williams, (Eds.), Theories in second language acquisition: An introduction (pp. 175-199). Mahwah, NJ: Erlbaum.

Harlen, W., \& James, M. (1997). Assessment and learning: differences and relationships between formative and summative assessment. Assessment in Education, 4(3), 365-379.

Hedgcock, J., \& Lefkowitz, N. (1994). Feedback on feedback: Assessing learner receptivity to teacher response in L2 composing. Journal of Second Language Writing, 3(2), 141-163.

Hernández Méndez, E., \& Reyes Cruz, M. D. R. (2012). Teachers' Perceptions About Oral Corrective Feedback and Their Practice in EFL Classrooms. Profile Issues in Teachers Professional Development, 14(2), 63-75.

Huang, B. H. (2013). The effects of accent familiarity and language teaching experience on raters' judgments of non-native speech. System, 41(3), 770-785.

Kartchava, E. (2006). Corrective feedback: novice ESL teachers' beliefs and practices (Master's thesis). Retrieved from http://www.concordia.ca/

Krashen, S. D. (1982). Principles and practices in second language acquisition. Oxford: Pergamon Press.

Li, S. (2010). The Effectiveness of Corrective Feedback in SLA: A Meta - Analysis. Language Learning, 60(2), 309-365.

Lightbown, P., \& Spada, N. (1990). Focus on form and corrective feedback in communicative language teaching. Studies in Second Language Acquisition, 12(4), 429-448.

Lyster, R. (1998). Negotiation of form, recasts, and explicit correction in relation to error types and learner repair in immersion classrooms. Language Learning, 48(2), 183-218.

Lyster, R., \& Ranta, L. (1997). Corrective feedback and learner uptake. Studies in Second Language Acquisition, 19(1), 37-66.

Lyster, R., \& Saito, K. (2010). Oral feedback in classroom SLA. Studies in Second Language Acquisition, 32(2), 265-302.

Mackey, A., Gass, S., \& McDonough, K. (2000). How do learners perceive interactional feedback?. Studies in Second Language Acquisition, 22(4), 471-497.

Maclellan, E. (2004). Initial knowledge states about assessment: Novice teachers' conceptualisations. Teaching and Teacher Education, 20(5), 523-535.

Moradkhani, S., \& Goodarzi, A. (2020). A Case Study of Three EFL Teachers' Cognition in Oral Corrective Feedback: Does Experience Make a Difference?. Issues in Language Teaching, 9(1), 183-211.

Mori, R. (2011). Teacher cognition in corrective feedback in Japan. System, 39(4), 451-467. 
Munro, M. J., \& Derwing, T. M. (2015). A prospectus for pronunciation research in the $21 \mathrm{st}$ century: A point of view. Journal of Second Language Pronunciation, 1(1), 11-42.

Murphy, D. (2011). An investigation of English pronunciation teaching in Ireland. English Today, 27(4), 10-18.

Nicholas, H., Lightbown, P. M., \& Spada, N. (2001). Recasts as feedback to language learners. Language Learning, 51(4), 719-758.

pronunciation: The case of Japanese learners of English. International Journal of Applied Linguistics, 24(2), 250-277.

Qutub, H. (2014). Performing Identity: Differences between Native and Nonnative Speakers of English in Gatekeeping Encounters. Arab World English Journal, 5(1).

Rahimi, M., \& Zhang, L. J. (2015). Exploring non-native English-speaking teachers' cognitions about corrective feedback in teaching English oral communication. System, 55, 111-122.

Razfar, A. (2010). Repair with confianza: Rethinking the context of corrective feedback for English learners (ELs). English Teaching-Practice and Critique, 9(2), 11-31.

Saito, K. (2011). Examining the role of explicit phonetic instruction in native-like and comprehensible pronunciation development: An instructed SLA approach to L2 phonology. Language Awareness, 20(1), 45-59.

Saito, K. (2014). Experienced teachers' perspectives on priorities for improved intelligible

Saito, K., \& Lyster, R. (2012a). Effects of Form - Focused Instruction and Corrective Feedback on L2 Pronunciation Development of/I/by Japanese Learners of English. Language Learning, 62(2), 595-633.

Saito, K., \& Lyster, R. (2012b). Investigating the pedagogical potential of recasts for L2 vowel acquisition. TESOL Quarterly, 46(2), 387-398.

Schmidt, R. (1983). Interaction, acculturation, and the acquisition of communicative competence. In N.Wolfson \& E. Judd (Eds.), Sociolinguistics and language acquisition (pp. 137-174). Rowley, M A: Newbury House.

Schmidt, R. W. (1990). The Role of Consciousness in Second Language Learning1. Applied Linguistics, 11(2), 129-158.

Sheen, Y. (2004). Corrective feedback and learner uptake in communicative classrooms across instructional settings. Language Teaching Research, 8(3), 263-300.

Sheen, Y. (2006). Exploring the relationship between characteristics of recasts and learner uptake. Language Teaching Research, 10(4), 361-392.

Uzum, B. (2010). Who gains more?: A case of motivation and corrective feedback in ESL classes. In J. M. Perren, K. Losey, D. O. Perren, \& A. Piippo (Eds.), Transforming Learning: Teaching \& Advocacy and ESL at the Crossroads. Paper presented at Selected Proceedings of 


\section{Macrothink}

International Journal of Linguistics

ISSN 1948-5425

2021, Vol. 13, No. 5

Both the 2009 and 2010 Michigan Teachers of English Speakers of Other Languages Conferences, Michigan (pp. 18-39). Michigan: Grand Rapids.

Van Ha, X., \& Murray, J. C. (2021). The impact of a professional development program on EFL teachers' beliefs about corrective feedback. System, 96, 102405.

VanPatten, B., \&Williams, J. (2007). Early theories in second language acquisition. In B. VanPatten, \& J. Williams, (Eds.), Theories in second language acquisition: An introduction (pp. 17-35). Mahwah, NJ: Erlbaum.

Wiliam, D. (2011). Embedded formative assessment. Bloomington, IN: Solution Tree Press.

Wiliam, D., \& Black, P. (1996). Meanings and consequences: a basis for distinguishing formative and summative functions of assessment?. British Educational Research Journal, 22(5), 537-548.

Yoshida, R. (2010). How do teachers and learners perceive corrective feedback in the Japanese language classroom?. The Modern Language Journal, 94(2), 293-314.

\section{Copyrights}

Copyright for this article is retained by the author(s), with first publication rights granted to the journal.

This is an open-access article distributed under the terms and conditions of the Creative Commons Attribution license (http://creativecommons.org/licenses/by/4.0/) 